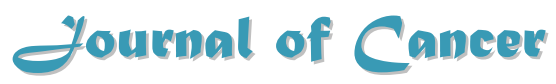

2010; 1:101-107

Review

(C) Ivyspring International Publisher. All rights reserved

\title{
Vitamin D in combination cancer treatment
}

\section{Yingyu Ma1 ${ }^{1}$ Donald L. Trump ${ }^{2}$ and Candace S. Johnson ${ }^{1}$ 龱}

1. Department of Pharmacology and Therapeutics, Roswell Park Cancer Institute, Buffalo, NY 14263, USA

2. Department of Medicine, Roswell Park Cancer Institute, Buffalo, NY 14263, USA

Corresponding author: candace.johnson@roswellpark.org

Published: 2010.07.15

\begin{abstract}
As a steroid hormone that regulates mineral homeostasis and bone metabolism, $I \alpha$, 25-dihydroxycholecalciferol (calcitriol) also has broad spectrum anti-tumor activities as supported by numerous epidemiological and experimental studies. Calcitriol potentiates the anti-tumor activities of multiple chemotherapeutics agents including DNA-damaging agents cisplatin, carboplatin and doxorubicin; antimetabolites 5-fluorouracil, cytarabine, hydroxyurea, cytarabine and gemcitabine; and microtubule-disturbing agents paclitaxel and docetaxel. Calcitriol elicits anti-tumor effects mainly through the induction of cancer cell apoptosis, cell cycle arrest, differentiation, angiogenesis and the inhibition of cell invasiveness by a number of mechanisms. Calcitriol enhances the cytotoxic effects of gamma irradiation and certain antioxidants and naturally derived compounds. Inhibition of calcitriol metabolism by 24-hydroxylase promotes growth inhibition effect of calcitriol. Calcitriol has been used in a number of clinical trials and it is important to note that sufficient dose and exposure to calcitriol is critical to achieve anti-tumor effect. Several trials have demonstrated that safe and feasible to administer high doses of calcitriol through intermittent regimen. Further well designed clinical trials should be conducted to better understand the role of calcitriol in cancer therapy.
\end{abstract}

Key words: vitamin D, calcitriol, cancer, chemotherapy

\section{Introduction}

Vitamin D is a steroid hormone that regulates calcium homeostasis, bone metabolism and a variety of other physiological functions (1). Vitamin D can be obtained from ultraviolet light-induced photobiogenesis in the skin or from the diet (1). In the skin, 7-dehydrocholesterol is converted to vitamin $\mathrm{D}_{3}$, which is hydroxylated to $25(\mathrm{OH}) \mathrm{D}_{3}$ by 25-hydroxylase in the liver and then to $1,25(\mathrm{OH})_{2} \mathrm{D}_{3}$ (1 $\alpha, 25$-dihydroxycholecalciferol, calcitriol), the hormonally active metabolite, by $1 \alpha$-hydroxylase in the kidney (1). Calcitriol is mainly catabolized by 24-hydroxylase (CYP24A1) to $1 \alpha, 24,25(\mathrm{OH})_{2} \mathrm{D}_{3}$ which loses its bioactivity (1).

Calcitriol acts through both genomic and non-genomic mechanisms (2). In genomic pathways, calcitriol binds to intracellular vitamin $\mathrm{D}$ receptor (VDR), which subsequently heterodimerizes with another nuclear receptor retinoid $X$ receptor (RXR). The heterodimer binds to vitamin $\mathrm{D}$ response element in target genes and leads to gene transcription regulation (1). In addition, calcitriol has rapid effects that are independent of gene transcription regulation, which are defined as non-genomic effects and not mediated directly through steroid receptor-ligand-DNA interaction. On the other hand, non-genomic actions may indirectly affect gene transcription via the regulation of intracellular signaling pathways that target transcription factors (3). Calcitriol induces a number of non-genomic responses including rapid intestinal absorption of calcium, release 
of calcium from intracellular stores, opening of voltage-gated calcium and chloride channels, and the activation of protein kinase $\mathrm{C}$, protein kinase $\mathrm{A}$, phosphatidylinositol-3 kinase (PI3K) and phospholipase $C(4)$.

\section{Vitamin D compounds in cancer prevention and treatment}

Numerous epidemiological and preclinical studies support a role of vitamin D compounds in cancer prevention and treatment in colorectal, breast, prostate, ovarian, bladder, lung and skin cancers and leukemia $(1,5,6)$. Low levels of plasma $25(\mathrm{OH}) \mathrm{D}_{3}$ are associated with higher cancer incidence and mortality in men in colorectal, breast, lung and prostate cancers (7-10). The broad spectrum anti-tumor effects of calcitriol and analogs are mostly based on inhibition of cancer cell proliferation and invasiveness, induction of differentiation and apoptosis, and promotion of angiogenesis.

Calcitriol has been studied in various combination treatments and shown synergistic or additive antitumor activities. Cisplatin (cis-diamminedichloro-platinum (II), cDDP) and its analog carboplatin (Di-amminecyclobutanedicarboxylatoplatinum, CBDCA) are widely used DNA-damaging agents. It is active in the treatment of testicular, ovarian, cervical, lung, bladder cancer and head and neck squamous cell carcinoma (SCC) $(11,12)$. Calcitriol enhances both carboplatin and cisplatin-mediated growth inhibition in breast cancer MCF-7 cells and prostate cancer LNCaP and DU145 cells $(13,14)$. Calcitriol potentiates cisplatin anti-tumor effect in a Y-79 human retinoblastoma xenograft model (15) and canine breast cancer, osteosarcoma, and mastocytoma cells (16). Ro23-7553 (1,25(OH) 2-16-ene-23-yne- $\left.\mathrm{D}_{3}\right)$, a calcitriol analog, inhibits tumor regrowth when combined with cisplatin in a SCC model system (17). Calcitriol promotes the expression of mitogen-activated protein kinase kinase kinase (MEKK-1) and the cleavage of caspase 3 when used in combination with cisplatin in SCC cells (18). Additional studies support these findings. SCC-VII and a calcitriol-resistant variant SCC (SCC-DR), generated by continuous culturing of SCC cells in calcitriol-containing media and has non-inducible VDR, are resistant to cisplatin (19). Pretreatment with calcitriol sensitizes SCC cells to cisplatin-induced growth inhibition and results in enhanced clonogenic cell kill in SCC. This effect is not seen in SCC-DR cells in vitro and in vivo. This sensitization may be due to restored apoptotic pathway, as indicated by enhanced cleavage of pro-caspase 10 and PARP and increased DNA fragmentation. Calcitriol and cisplatin suppress SCC tumor growth much bet- ter than either agent alone (19). Further study shows that calcitriol increased the protein level of p73, a p53 family member, which contributed to calcitriol and cisplatin-mediated growth inhibition in SCC cells (19).

Calcitriol sensitizes breast cancer cells to another DNA-damaging agent doxorubicin through the inhibition of the expression and activity of cytoplasmic antioxidant enzyme $\mathrm{Cu} / \mathrm{Zn}$ superoxide dismutase, which subsequently increases the oxidative damage by doxorubicin (20). Tamoxifen and calcitriol or its analog EB1089, KH1060, CB966 or OCT used together lead to enhanced growth inhibition in breast cancer cells MCF-7 than either agent alone (21). OCT and tamoxifen also inhibit MCF-7 xenograft tumor progression (22).

Calcitriol also additively or synergistically potentiates the anti-tumor activity of other types of chemotherapeutic agents. Calcitriol promotes tumor cell sensitivity to several antimetabolites, which interfere with the synthesis of RNA and DNA. Calcitriol enhances cellular sensitivity of human colon cancer cells to 5-fluorouracil through calcium-sensing receptor (23). When added together or immediately after ara-C (cytarabine), calcitriol promotes the accumulation of DNA fragments and cytotoxicity (24). Calcitriol and cytarabine combination has been used in clinic as the minimally intensive chemotherapy, and prolonged remission in elderly patients with acute myeloid leukemia (AML) and myelodysplastic syndrome (MDS) (25, 26). Adenosine deaminase-resistant analog fludarabine synergistically enhances calcitriol-induced differentiation of human monoblastic leukemia U937 cells (27). Hydroxyurea, cytarabine or camptothecin acts synergistically with calcitriol to inhibit human monoblastic leukemia U937 cell growth (28). Hydroxyurea also promotes calcitriol-mediated U937 cell differentiation (28). Gemcitabine is a widely used antimetabolite, and the combination of gemcitabine and cisplatin is the current standard chemotherapy regimen for locally advanced and metastatic bladder cancer $(29,30)$. Calcitriol enhances caspase-dependent apoptosis and synergistically promotes the anti-proliferative effects of gemcitabine and cisplatin in human bladder cancer model systems T24 and UMUC3 (31). We have shown in vitro in SCC cells that p73 is important in calcitriol antiproliferative effect; we are also examining p73 status in vivo in human transitional cell carcinoma. The expression of p73 protein is lower in human bladder cancer tissue compared with adjacent normal tissue in 3 out of 4 pairs as assessed by immunoblot analysis (31). Calcitriol augments p73 protein level in T24 and UMUC3 bladder cancer cells, which may contribute to this growth inhibition (31). Pretreatment 
with calcitriol in combination with gemcitabine and cisplatin markedly inhibits T24 tumor growth in nude mice (31). Anti-tumor activity of gemcitabine is also augmented by calcitriol in Capan-1 human pancreatic cancer model system, as suggested by enhanced growth inhibition, apoptosis, inhibition of Akt survival pathway and xenograft tumor growth (32).

Calcitriol potentiates antitumor activity of microtubule-disrupting agents such as paclitaxel $(33,34)$ and docetaxel (35). This effect is associated with reduced expression level of p21 in prostate cancer cell PC3 (33) or increased Bcl-2 phosphorylation in breast cancer cells (34), and multidrug resistance-associated protein 1 (35), respectively. Calcitriol analog 1,25(OH) ${ }_{2}-16$-ene-23-yne-19-nor-26,27-F6- $\mathrm{D}_{3}$ (LH) or EB1089 also potentiates antitumor activity of paclitaxel in breast cancer model systems (36). Calcitriol analog ILX 23-7553 additively enhances the antitumor effects of both adriamycin and ionizing irradiation in breast tumor cells MCF-7 through growth inhibition and apoptosis induction (37). These substantial data suggest that the addition of calcitriol to multiple chemotherapy regimens increases the activity of such treatments and potentially a better response rate to the regimens.

VDR forms heterodimer in association with RXR. RXR ligand 9-cis-retinoic acid (9-cis-RA) combined with calcitriol results in delayed tumor progression in the prostate PC3 tumor xenograft model in nude mice (38). This combination treatment results in direct binding of VDR/RXR heterodimer to the promoter region of human telomerase reverse transcriptase (hTERT) which inhibits the expression of hTERT and subsequently leads to decreased telomerase activity in prostate cancer cells (38). Calcitriol analog 20-epi-22oxa-24a,26a,27a-tri-homo- $1 \alpha, 25(\mathrm{OH})_{2} \mathrm{D}_{3}$

(KH1060) synergizes with 9-cis-RA to inhibit the growth and promote the differentiation of acute promyelocytic leukemia cells NB4 (39) and myeloblastic cells HL-60 (40). The combination leads to increased apoptosis which is accompanied by reduced Bcl-2 expression and increased Bax expression (39).

The antitumor activity of calcitriol may also involve histone deacetylation. Combining histone deacetylase inhibitor sodium butyrate or trichostatin A with calcitriol or its analog LH or $1 \alpha, 25-(\mathrm{OH})_{2}-16,23 \mathrm{E}-$ diene-26,27-hexafluoride- $\mathrm{D}_{3}$ (LT) synergistically suppresses calcitriol or analog-induced growth inhibition in prostate cancer cell lines LNCaP, PC3 and DU145 (41). This effect is mediated by enhanced apoptosis instead of induction of cell cycle arrest (41).

Besides chemotherapy, vitamin D is also used in combination with other types of cancer treatment.
Calcitriol or its less calcaemic analogue $19-$ nor- $1 \alpha, 25-(\mathrm{OH})_{2} \mathrm{D}_{2}$ acts synergistically with ironizing radiation to inhibit the growth and apoptosis of LNCaP prostate cancer cells and primary tumor cells (42). EB1089 potentiates the antitumor activity of ironizing radiation partially through increased apoptosis in breast cancer model system MCF-7 (43). Breast cancer cells overexpress one of the NF- $\mathrm{KB}$ subunits RelB, which promotes cancer cell survival. Calcitriol treatment results in reduced mRNA and protein levels of RelB and its target genes survivin, Bcl-2 and MnSOD, and sensitizes the breast cancer cells Hs578T and NF639 to gamma-irradiation. Overexpression of RelB enhances NF639 cells survival following calcitriol and irradiation treatment (44). Calcitriol pretreatment for $24 \mathrm{~h}$ enhances the phototoxic response of human SCC A431 cells to methyl aminolaevulinate-based photodynamic therapy (45).

Non-specific cyclooxygenase (COX) inhibitors acetyl salicylic acid or indomethacin in combination with calcitriol markedly induce differentiation of leukemia cell lines into monocytes and cell cycle arrest at G1 phase (46). Cell differentiation is dependent on phosphorylation of Raf1 (46). The combination of ibuprofen, a non-steroidal anti-inflammatory drug (NSAID), and calcitriol results in greater growth inhibition and G1 cell cycle arrest in human prostate cancer LNCaP cells compared to either agent alone (47). A calcitriol analog 22-oxa- $1 \alpha, 25-(\mathrm{OH})_{2} \mathrm{D}_{3}$, when used together with vitamin $\mathrm{K}_{2}$, promotes leukemia cells HL-60 differentiate into monocytes as examined by morphology and cell surface CD14 expression in a synergistic nature (48). This combination also induces cell cycle arrest at G0/G1 phase; however, it suppresses apoptosis compared to vitamin $\mathrm{K}_{2}$ alone (48). Carnosic acid, a plant-derived polyphenolic antioxidant, enhances the monocytic differentiation effects of calcitriol in human myeloid leukemia cells HL60 (49). Decreased intracellular reactive oxygen species, increased intracellular glutathione, and activation of Raf-1/MEK1/ERK1/2 pathway are observed with the combination treatment (49). Bryostatin-1, a marine bryozoan-derived natural compound, has antitumor activities in both solid and lymphoid tumors (50). Bryostatin-1 synergizes with calcitriol to induce monocytic differentiation of NB4 cells $(50,51)$, which is associated with G1 phase cell cycle arrest, decreased cell growth and increased plastic adhesion (50). $25(\mathrm{OH}) \mathrm{D}_{3}$, when used together with iron deprivation agents including iron chelators or transferrin receptor antibody A24, induces the differentiation of myeloid leukemia cell lines and primary myeloblasts from AML patients into monocytes/macrophages (52). These effects are dependent on the increased level of 
reactive oxygen species and the activation of JNK MAPK pathway (52).

Interaction of calcitriol with certain agents results in enhanced calcitriol anti-tumor activity. Administration of dexamethasone (Dex), which reduces calcitriol-induced hypercalcemia, prior to calcitriol inhibits SCC cell proliferation compared to calcitriol alone (53). Combined treatment with Dex and calcitriol reduces SCC xenograft tumor growth. These findings are associated with the observations that Dex enhances VDR expression in SCC cells and VDR ligand binding activities in tumor cell extracts and kidneys but decreases that in intestinal mucosa (53). Further studies show that the combination of calcitriol and Dex apoptosis and cell cycle arrest at G0/G1 in SCC cells (54). This combination also suppresses the activation of Akt and ERK1/2 pathways (54).

The effect of calcitriol is modulated by its metabolizing enzymes. The primary vitamin $\mathrm{D}_{3}$ inactivating enzyme CYP24A1, a mitochondrial cytochrome $\mathrm{P} 450$, induces calcitriol degradation and thereby inhibits calcitriol biological activity. The broad spectrum cytochrome P450 inhibitor ketoconazole (KTZ) or a specific CYP24A1 inhibitor RC2204, which effectively inhibits the expression and enzyme activity of CYP24A1 in PC3 cells and mice kidney tissue, synergistically inhibits the anti-proliferative effect of calcitriol in human prostate PC3 cells (55). Dex is administered together with KTZ to minimize calcitriol-mediated hypercalcemia. Enhanced apoptosis is observed which does not involve caspase 3 activation but the translocation of apoptosis inducing factor (AIF) to the nucleus. Calcitriol and ketoconazle/Dex combination enhances the growth inhibition observed with calcitriol alone in PC3 xenograft tumor mouse model (55). KTZ also potentiates the anti-proliferative effect of calcitriol or its analog EB1089 in prostate cancer cells (56). An imidazole derivative liarozole inhibits CYP24 activity in prostate cancer cells DU145 and thus sensitizes these cells to calcitriol-mediated growth inhibition, which is associated with increased VDR expression (57).

RRR-alpha-vitamin E succinate (VES), one of the most effective vitamin $\mathrm{E}$ forms, induces VDR expression in prostate cancer cells (58). Pretreatment with VES synergistically enhances calcitriol-mediated growth inhibition of prostate cancer cells in vitro and reduces the rate of prostate cancer xenograft tumor growth (58), which allows for a low-dose calcitriol to be administered. A glutathione-depleting compound, menadione, sensitizes breast cancer cells MCF-7 to calcitriol-mediated growth inhibition, which may be caused, at least in part, by the increased oxidative stress, as shown by enhanced ROS production (59).
Genistein, an isoflavone found in soybeans and a number of plants, in combination with calcitriol, inhibits cell growth in human prostate LNCaP cells, which is dependent on increased expression of p21 and associated with increased VDR expression (60). Another study shows that genistein and calcitriol further reduce prostate DU145 cell proliferation compared to either agent alone (61). The mechanisms for this effect may involve the induction of mRNA expression and enzyme activity of CYP24 by genistein which leads to prolonged half-life of calcitriol (61). Increased expression of VDR protein, VDR transcriptional activity, and the expression of VDR target genes are also observed in the combination treatment group (61). A medicinal herb ginseng (Panax ginseng C.A. Meyer, Araliaceae) promotes calcitriol-induced the differentiation of leukemia cells HL-60 into monocytes as assessed by expression levels of CD14 and CD11b (62). This effect may be mediated by the ERK1/2 and PKC, but not PI3K pathway (62).

Phosphorylated prolactin (PRL) antagonizes the proliferation promoting effect of unmodified PRL. Molecular mimicry of naturally phosphorylated human PRL at the major phosphorylation site S179, S179D (PRL), sensitizes relatively vitamin D-insensitive prostate cancer cells DU-145 and PC3 to calcitriol-mediated anti-proliferative effect and apoptosis, which is associated with increased VDR and p21 expression (63). Secreted protein acidic and rich in cysteine (SPARC; osteonectin, BM-40), a family member of matricellular proteins including thrombospondins, tenascin, and osteopontin, may serve as a tumor suppressor (64). Compared with parental MIP101 colorectal cancer cells, calcitriol markedly reduces cell growth and enhances calcitriol alone- or calcitriol+fluorouracil-induced apoptosis in SPARC-overexpressing MIP101 cells (64). Calcitriol treatment also suppresses the phosphorylation of Akt and the expression of Bcl-2 family member BAD (64).

Calcitriol has been utilized in a number of clinical studies, either alone or in combination with Dex or cytotoxic agents, which has been reviewed $(65,66)$. It is important to emphasize that anti-tumor activity of calcitriol is dependent on its dose and exposure according to preclinical studies. Exposure to high concentrations of calcitriol is necessary to achieve anti-tumor results. Calcitriol or its analog Ro23-7553 delays SCC xenograft tumor growth in a dose dependent manner (67). Calcitriol of $2.5 \mu \mathrm{g} /$ mouse administered twice a week results in a markedly stronger tumor suppression compared with once a week regimen in human pancreatic cancer model system Capan-1 (32). Pharmacokinectic (PK) studies indicate that calcitriol of $0.125 \mu \mathrm{g} /$ mouse results in a 
$\mathrm{C}_{\max }>10.0 \mathrm{ng} / \mathrm{ml}$ and AUC $>40.0 \mathrm{ng} \mathrm{h} / \mathrm{mL}$ in normal mice (68), which exceeds the concentration needed for calcitriol anti-tumor activity in vitro.

Although multiple clinical studies have been conducted with calcitriol or its analogs, the anti-tumor results are largely disappointing. This may be due to the fact that calcitriol or its analogs has been used at much lower doses than maximum tolerated dose (MTD) with the concern of dose-limiting hypercalcemia $(69,70)$. We and others demonstrate that sufficient doses of calcitriol to achieve exposure similar to those seen in preclinical models can be safely administered by high dose intermittent regimen (once weekly or QDx3 weekly) (69, 71-73). A recent phase I clinical trial demonstrates that the MTD of calcitriol (i.v.) is $74 \mu \mathrm{g} /$ week when administered with gefitinib (70). The $C_{\max }$ of calcitriol at the MTD is $6.68 \pm 1.42$ $\mathrm{ng} / \mathrm{ml}(16 \pm 3.40 \mathrm{nmol} / \mathrm{L})$, which is much higher than the dose needed to elicit anti-tumor effect in preclinical studies (70). The area under the curve (AUC) of calcitriol at the MTD is $35.65 \pm 8.01 \mathrm{ng} \mathrm{h} / \mathrm{mL}(70)$. In comparison, $75 \mu \mathrm{g}$ of DN101, a weekly oral formulation of calcitriol, results in a lower $C_{\max }(3.8 \mathrm{nmol} / \mathrm{L})$ but similar AUC (38.4 ng h/mL) (74). These results show that high doses of calcitriol can be administered alone or in combination with other agents to elicit or enhance the anti-tumor effects.

\section{Summary}

In summary, calcitriol has shown potential in enhancing the antitumor activities of a variety of cytotoxic or differentiating agents. The combination treatment studies with calcitriol do provide evidence and support for the continued study of calcitriol in cancer chemotherapies.

\section{Conflict of Interest}

The authors have declared that no conflict of interest exists.

\section{References}

1. Brown AJ, Dusso A, Slatopolsky E. Vitamin D. Am J Physiol 1999; 277: F157-75.

2. Sutton AL, MacDonald PN. Vitamin D: more than a "bone-a-fide" hormone. Mol Endocrinol 2003; 17: 777-91.

3. Losel R, Wehling M. Nongenomic actions of steroid hormones. Nat Rev Mol Cell Biol 2003; 4: 46-56.

4. Norman AW, Mizwicki MT, Norman DP. Steroid-hormone rapid actions, membrane receptors and a conformational ensemble model. Nat Rev Drug Discov 2004; 3: 27-41.

5. Garland CF, Garland FC, Gorham ED, et al. The role of vitamin D in cancer prevention. Am J Public Health 2006; 96: 252-61.

6. Giovannucci E, Liu Y, Rimm EB, et al. Prospective study of predictors of vitamin $\mathrm{D}$ status and cancer incidence and mortality in men. J Natl Cancer Inst 2006; 98: 451-9.
7. Giovannucci E, Liu Y, Stampfer MJ, Willett WC. A prospective study of calcium intake and incident and fatal prostate cancer. Cancer Epidemiol Biomarkers Prev 2006; 15: 203-10.

8. Giovannucci E. Vitamin D and cancer incidence in the Harvard cohorts. Ann Epidemiol 2009; 19: 84-8.

9. $\mathrm{Ng} \mathrm{K}$, Meyerhardt JA, $\mathrm{Wu} \mathrm{K}$, et al. Circulating 25-hydroxyvitamin d levels and survival in patients with colorectal cancer. J Clin Oncol 2008; 26: 2984-91.

10. Kilkkinen A, Knekt P, Heliovaara M, et al. Vitamin D status and the risk of lung cancer: a cohort study in Finland. Cancer Epidemiol Biomarkers Prev 2008; 17: 3274-8.

11. Zamble DB, Lippard SJ. Cisplatin and DNA repair in cancer chemotherapy. Trends Biochem Sci 1995; 20: 435-9.

12. Cohen SM, Lippard SJ. Cisplatin: from DNA damage to cancer chemotherapy. Prog Nucleic Acid Res Mol Biol 2001; 67: 93-130.

13. Cho YL, Christensen C, Saunders DE, et al. Combined effects of 1,25-dihydroxyvitamin D3 and platinum drugs on the growth of MCF-7 cells. Cancer Res 1991; 51: 2848-53.

14. Moffatt KA, Johannes WU, Miller GJ. 1Alpha,25dihydroxyvitamin D3 and platinum drugs act synergistically to inhibit the growth of prostate cancer cell lines. Clin Cancer Res 1999; 5: 695-703.

15. Kulkarni AD, van Ginkel PR, Darjatmoko SR, Lindstrom MJ, Albert DM. Use of combination therapy with cisplatin and calcitriol in the treatment of Y-79 human retinoblastoma xenograft model. Br J Ophthalmol 2009; 93: 1105-8.

16. Rassnick KM, Muindi JR, Johnson CS, et al. In vitro and in vivo evaluation of combined calcitriol and cisplatin in dogs with spontaneously occurring tumors. Cancer Chemother Pharmacol 2008; 62: 881-91.

17. Light BW, Yu WD, McElwain MC, Russell DM, Trump DL, Johnson CS. Potentiation of cisplatin antitumor activity using a vitamin $\mathrm{D}$ analogue in a murine squamous cell carcinoma model system. Cancer Res 1997; 57: 3759-64.

18. Hershberger PA, McGuire TF, Yu WD, et al. Cisplatin potentiates 1,25-dihydroxyvitamin D3-induced apoptosis in association with increased mitogen-activated protein kinase kinase kinase 1 (MEKK-1) expression. Mol Cancer Ther 2002; 1: 821-9.

19. Ma Y, Yu WD, Hershberger PA, et al. 1alpha,25-Dihydroxyvitamin D3 potentiates cisplatin antitumor activity by p73 induction in a squamous cell carcinoma model. Mol Cancer Ther 2008; 7: 3047-55.

20. Ravid A, Rocker D, Machlenkin A, et al. 1,25-Dihydroxyvitamin D3 enhances the susceptibility of breast cancer cells to doxorubicin-induced oxidative damage. Cancer Res 1999; 59: 862-7.

21. Vink-van Wijngaarden T, Pols HA, Buurman CJ, et al. Inhibition of breast cancer cell growth by combined treatment with vitamin D3 analogues and tamoxifen. Cancer Res 1994; 54: 5711-7.

22. Abe-Hashimoto J, Kikuchi T, Matsumoto T, Nishii Y, Ogata E, Ikeda K. Antitumor effect of 22-oxa-calcitriol, a noncalcemic analogue of calcitriol, in athymic mice implanted with human breast carcinoma and its synergism with tamoxifen. Cancer Res 1993; 53: 2534-7.

23. Liu G, Hu X, Chakrabarty S. Vitamin D mediates its action in human colon carcinoma cells in a calcium-sensing receptor-dependent manner: downregulates malignant cell behavior and the expression of thymidylate synthase and survivin and promotes cellular sensitivity to 5-FU. Int J Cancer 2010; 126: 631-9.

24. Studzinski GP, Reddy KB, Hill HZ, Bhandal AK. Potentiation of 1-beta-D-arabinofuranosylcytosine cytotoxicity to HL-60 cells by 1,25-dihydroxyvitamin D3 correlates with reduced rate of maturation of DNA replication intermediates. Cancer Res 1991; 51: 3451-5.

25. Slapak CA, Desforges JF, Fogaren T, Miller KB. Treatment of acute myeloid leukemia in the elderly with low-dose cytara- 
bine, hydroxyurea, and calcitriol. Am J Hematol 1992; 41: 178-83.

26. Ferrero D, Campa E, Dellacasa C, Campana S, Foli C, Boccadoro M. Differentiating agents + low-dose chemotherapy in the management of old/poor prognosis patients with acute myeloid leukemia or myelodysplastic syndrome. Haematologica 2004; 89: 619-20.

27. Niitsu N, Umeda M, Honma Y. Myeloid and monocytoid leukemia cells have different sensitivity to differentiation-inducing activity of deoxyadenosine analogs. Leuk Res 2000; 24: 1-9.

28. Makishima M, Okabe-Kado J, Honma Y. Growth inhibition and differentiation induction in human monoblastic leukaemia cells by 1alpha-hydroxyvitamin $\mathrm{D}$ derivatives and their enhancement by combination with hydroxyurea. Br J Cancer 1998; 77: 33-9.

29. Sternberg CN, Donat SM, Bellmunt J, et al. Chemotherapy for bladder cancer: treatment guidelines for neoadjuvant chemotherapy, bladder preservation, adjuvant chemotherapy, and metastatic cancer. Urology 2007; 69: 62-79.

30. Barocas DA, Clark PE. Bladder cancer. Curr Opin Oncol 2008; 20: 307-14.

31. Ma Y, Yu WD, Trump DL, Johnson CS. 1,25D(3) Enhances antitumor activity of gemcitabine and cisplatin in human bladder cancer models. Cancer 2010; 116: 3294-303.

32. Yu WD, Ma Y, Flynn G, et al. Calcitriol enhances gemcitabine anti-tumor activity in vitro and in vivo by promoting apoptosis in a human pancreatic carcinoma model system. Cell Cycle 2010; in press.

33. Hershberger PA, Yu WD, Modzelewski RA, Rueger RM, Johnson CS, Trump DL. Calcitriol (1,25-dihydroxycholecalciferol) enhances paclitaxel antitumor activity in vitro and in vivo and accelerates paclitaxel-induced apoptosis. Clin Cancer Res 2001; 7: 1043-51.

34. Wang Q, Yang W, Uytingco MS, Christakos S, Wieder R. 1,25-Dihydroxyvitamin D3 and all-trans-retinoic acid sensitize breast cancer cells to chemotherapy-induced cell death. Cancer Res 2000; 60: 2040-8.

35. Ting HJ, Hsu J, Bao BY, Lee YF. Docetaxel-induced growth inhibition and apoptosis in androgen independent prostate cancer cells are enhanced by 1alpha,25-dihydroxyvitamin D3. Cancer Lett 2007; 247: 122-9.

36. Koshizuka K, Koike M, Asou H, et al. Combined effect of vitamin D3 analogs and paclitaxel on the growth of MCF-7 breast cancer cells in vivo. Breast Cancer Res Treat 1999; 53: 113-20.

37. Chaudhry M, Sundaram S, Gennings C, Carter H, Gewirtz DA. The vitamin D3 analog, ILX-23-7553, enhances the response to adriamycin and irradiation in MCF-7 breast tumor cells. Cancer Chemother Pharmacol 2001; 47: 429-36.

38. Ikeda $\mathrm{N}$, Uemura $\mathrm{H}$, Ishiguro $\mathrm{H}$, et al. Combination treatment with 1alpha,25-dihydroxyvitamin D3 and 9-cis-retinoic acid directly inhibits human telomerase reverse transcriptase transcription in prostate cancer cells. Mol Cancer Ther 2003; 2: $739-46$.

39. Elstner E, Linker-Israeli M, Le J, et al. Synergistic decrease of clonal proliferation, induction of differentiation, and apoptosis of acute promyelocytic leukemia cells after combined treatment with novel 20-epi vitamin D3 analogs and 9-cis retinoic acid. J Clin Invest 1997; 99: 349-60.

40. Elstner E, Linker-Israeli M, Umiel T, et al. Combination of a potent 20-epi-vitamin D3 analogue (KH 1060) with 9-cis-retinoic acid irreversibly inhibits clonal growth, decreases bcl-2 expression, and induces apoptosis in HL-60 leukemic cells. Cancer Res 1996; 56: 3570-6.

41. Rashid SF, Moore JS, Walker E, et al. Synergistic growth inhibition of prostate cancer cells by 1 alpha, 25 Dihydroxyvitamin $\mathrm{D}(3)$ and its 19-nor-hexafluoride analogs in combination with either sodium butyrate or trichostatin A. Oncogene 2001; 20: 1860-72.

42. Dunlap N, Schwartz GG, Eads D, et al. 1alpha,25-dihydroxyvitamin $\mathrm{D}(3)$ (calcitriol) and its analogue, 19-nor-1alpha, $25(\mathrm{OH})(2) \mathrm{D}(2)$, potentiate the effects of ionising radiation on human prostate cancer cells. Br J Cancer 2003; 89: 746-53.

43. Sundaram S, Sea A, Feldman S, et al. The combination of a potent vitamin D3 analog, EB 1089, with ionizing radiation reduces tumor growth and induces apoptosis of MCF-7 breast tumor xenografts in nude mice. Clin Cancer Res 2003; 9: 2350-6.

44. Mineva ND, Wang X, Yang S, et al. Inhibition of RelB by 1,25-dihydroxyvitamin D3 promotes sensitivity of breast cancer cells to radiation. J Cell Physiol 2009; 220: 593-9.

45. Cicarma E, Tuorkey M, Juzeniene A, Ma LW, Moan J. Calcitriol treatment improves methyl aminolaevulinate-based photodynamic therapy in human squamous cell carcinoma A431 cells. Br J Dermatol 2009; 161: 413-8.

46. Jamshidi F, Zhang J, Harrison JS, Wang X, Studzinski GP. Induction of differentiation of human leukemia cells by combinations of COX inhibitors and 1,25-dihydroxyvitamin D3 involves Raf1 but not Erk 1/2 signaling. Cell Cycle 2008; 7: 917-24.

47. Gavrilov V, Steiner M, Shany S. The combined treatment of 1,25-dihydroxyvitamin D3 and a non-steroid anti-inflammatory drug is highly effective in suppressing prostate cancer cell line (LNCaP) growth. Anticancer Res 2005; 25: 3425-9.

48. Funato K, Miyazawa K, Yaguchi M, Gotoh A, Ohyashiki K. Combination of 22-oxa-1,25-dihydroxyvitamin $\mathrm{D}(3)$, a vitamin $\mathrm{D}(3)$ derivative, with vitamin $\mathrm{K}(2)$ (VK2) synergistically enhances cell differentiation but suppresses VK2-inducing apoptosis in HL-60 cells. Leukemia 2002; 16: 1519-27.

49. Danilenko M, Wang Q, Wang X, Levy J, Sharoni Y, Studzinski GP. Carnosic acid potentiates the antioxidant and prodifferentiation effects of 1alpha,25-dihydroxyvitamin D3 in leukemia cells but does not promote elevation of basal levels of intracellular calcium. Cancer Res 2003; 63: 1325-32.

50. Clark CS, Konyer JE, Meckling KA 1alpha,25-dihydroxyvitamin D3 and bryostatin-1 synergize to induce monocytic differentiation of NB4 acute promyelocytic leukemia cells by modulating cell cycle progression. Exp Cell Res 2004; 294: 301-11.

51. Song XD, Norman AW. Bryostatin-1 and 1alpha,25-dihydroxyvitamin D3 synergistically stimulate the differentiation of NB4 acute promyelocytic leukemia cells. Leukemia 1999; 13: 275-81.

52. Callens C, Coulon S, Naudin J, et al. Targeting iron homeostasis induces cellular differentiation and synergizes with differentiating agents in acute myeloid leukemia. J Exp Med 2010; 207: 731-50.

53. Yu WD, McElwain MC, Modzelewski RA, et al. Enhancement of 1,25-dihydroxyvitamin D3-mediated antitumor activity with dexamethasone. J Natl Cancer Inst 1998; 90: 134-41.

54. Bernardi RJ, Trump DL, Yu WD, McGuire TF, Hershberger PA, Johnson CS. Combination of 1alpha,25-dihydroxyvitamin D(3) with dexamethasone enhances cell cycle arrest and apoptosis: role of nuclear receptor cross-talk and Erk/ Akt signaling. Clin Cancer Res 2001; 7: 4164-73.

55. Muindi JR, Yu WD, Ma Y, et al. CYP24A1 Inhibition Enhances the Antitumor Activity of Calcitriol. Endocrinology 2010; in press.

56. Peehl DM, Seto E, Hsu JY, Feldman D. Preclinical activity of ketoconazole in combination with calcitriol or the vitamin D analogue EB 1089 in prostate cancer cells. J Urol 2002; 168: 1583-8

57. Ly LH, Zhao XY, Holloway L, Feldman D. Liarozole acts synergistically with 1alpha,25-dihydroxyvitamin D3 to inhibit 
growth of DU 145 human prostate cancer cells by blocking 24-hydroxylase activity. Endocrinology 1999; 140: 2071-6.

58. Yin Y, Ni J, Chen M, Guo Y, Yeh S. RRR-alpha-vitamin E succinate potentiates the antitumor effect of calcitriol in prostate cancer without overt side effects. Clin Cancer Res 2009; 15: 190-200.

59. Marchionatti AM, Picotto G, Narvaez CJ, Welsh J, Tolosa de Talamoni NG. Antiproliferative action of menadione and 1,25(OH)2D3 on breast cancer cells. J Steroid Biochem Mol Biol 2009; 113: 227-32.

60. Rao A, Coan A, Welsh JE, Barclay WW, Koumenis C, Cramer SD. Vitamin D receptor and p21/WAF1 are targets of genistein and 1,25-dihydroxyvitamin D3 in human prostate cancer cells. Cancer Res 2004; 64: 2143-7.

61. Swami S, Krishnan AV, Peehl DM, Feldman D. Genistein potentiates the growth inhibitory effects of 1,25-dihydroxyvitamin D3 in DU145 human prostate cancer cells: role of the direct inhibition of CYP24 enzyme activity. Mol Cell Endocrinol 2005; 241: 49-61.

62. Kim SH, Cho SS, Simkhada JR, et al. Enhancement of 1,25-dihydroxyvitamin D3- and all-trans retinoic acid-induced HL-60 leukemia cell differentiation by Panax ginseng. Biosci Biotechnol Biochem 2009; 73: 1048-53.

63. $\mathrm{Wu} \mathrm{W}$, Zanello L, Walker AM. S179D prolactin sensitizes human prostate cancer cells such that physiological concentrations of 1, 25 dihydroxy vitamin D3 result in growth inhibition and cell death. Prostate 2007; 67: 1498-506.

64. Taghizadeh F, Tang MJ, Tai IT. Synergism between vitamin D and secreted protein acidic and rich in cysteine-induced apoptosis and growth inhibition results in increased susceptibility of therapy-resistant colorectal cancer cells to chemotherapy. Mol Cancer Ther 2007; 6: 309-17.

65. Trump DL, Hershberger PA, Bernardi RJ, et al. Anti-tumor activity of calcitriol: pre-clinical and clinical studies. J Steroid Biochem Mol Biol 2004; 89-90: 519-26.

66. Trump DL, Deeb KK, Johnson CS. Vitamin D: considerations in the continued development as an agent for cancer prevention and therapy. Cancer J 2010; 16: 1-9.

67. McElwain MC, Modzelewski RA, Yu WD, Russell DM, Johnson CS. Vitamin D: an antiproliferative agent with potential for therapy of squamous cell carcinoma. Am J Otolaryngol 1997; 18: 293-8.

68. Muindi JR, Modzelewski RA, Peng Y, Trump DL, Johnson CS. Pharmacokinetics of 1alpha,25-dihydroxyvitamin D3 in normal mice after systemic exposure to effective and safe antitumor doses. Oncology 2004; 66: 62-6.

69. Smith DC, Johnson CS, Freeman CC, Muindi J, Wilson JW, Trump DL. A Phase I trial of calcitriol (1,25-dihydroxycholecalciferol) in patients with advanced malignancy. Clin Cancer Res 1999; 5: 1339-45.

70. Fakih MG, Trump DL, Muindi JR, et al. A phase I pharmacokinetic and pharmacodynamic study of intravenous calcitriol in combination with oral gefitinib in patients with advanced solid tumors. Clin Cancer Res 2007; 13: 1216-23.

71. Beer TM, Munar M, Henner WD. A Phase I trial of pulse calcitriol in patients with refractory malignancies: pulse dosing permits substantial dose escalation. Cancer 2001; 91: 2431-9.

72. Muindi JR, Peng Y, Potter DM, et al. Pharmacokinetics of high-dose oral calcitriol: results from a phase 1 trial of calcitriol and paclitaxel. Clin Pharmacol Ther 2002; 72: 648-59.

73. Beer TM, Javle MM, Ryan CW, et al. Phase I study of weekly DN-101, a new formulation of calcitriol, in patients with cancer. Cancer Chemother Pharmacol 2007; 59: 581-7.

74. Beer TM, Javle M, Lam GN, Henner WD, Wong A, Trump DL. Pharmacokinetics and tolerability of a single dose of DN-101, a new formulation of calcitriol, in patients with cancer. Clin Cancer Res 2005; 11: 7794-9. 